\title{
Climatic Variations, Trends and Drought Frequency in Dejen District, Nile Basin of Ethiopia
}

\author{
${ }^{1 *}$ AMARE, ZY $;{ }^{2}$ AYOADE, JO; ${ }^{2}$ ADELEKAN, IO $;{ }^{3}$ ZELEKE, MT \\ ${ }^{1 *}$ Pan African University, Life and Earth Sciences Institute (Including Health and Agriculture), (PAULESI), University of Ibadan, Ibadan, \\ Nigeria \\ ${ }^{2}$ Department of Geography, Faculty of the Social Sciences, University of Ibadan, Ibadan, Nigeria \\ *Corresponding Author: E-mail: zerihun.yohannes19@gmail.com \\ ${ }^{3}$ Department of Geography and Environmental Studies, DebreTabor University, Debre Tabor, Ethiopia
}

\begin{abstract}
Temperature and rainfall variability affect systems such as water, agriculture, health, tourism, coastal areas, and biodiversity. This study examined climatic variability, and trends in Dejen district, Nile Basin of Ethiopia. The trends in temperature and rainfall over the period 19792014 were computed and tested for statistical significance. Results indicated a significant increase in temperature consistent with global temperature pattern. The decreasing trend in rainfall is contrary to the projections of a climate model for East Africa.The results show that the mean annual temperature increased by $1.66^{\circ} \mathrm{C}$. The maximum and minimum temperatures also rose by $2.16^{\circ} \mathrm{C}$ and $1.91{ }^{\circ} \mathrm{C}$ respectively. The yearly rainfall declined by 399.96 millimeters. From 36 years of observation, 2002 and 2012 received below the average rainfall and characterized by arid years while 2008, 2011, 2013, 2014 years were moderately dry. The year 1983, 1986,1987,1996,1998, and 2010 were moderately wet. Among these negative patterns, the year 2002 and 2012 were extreme drought years. In the Nile Basin of Ethiopia, the variability and trends of temperature and rainfall, which hinders agricultural production are increasing and expected to increase in the future. This implies that the country specifically the study area whose mainstay depends on agriculture must cope with further warming, low, and erratic rainfall, and frequent climatic extremes.
\end{abstract}

DOI: https://dx.doi.org/10.4314/jasem.v21i7.2

COPYRIGHT: Copyright $\odot 2017$ Amare et al. This is an open access article distributed under the Creative Commons Attribution License (CCL), which permits unrestricted use, distribution, and reproduction in any medium, provided the original work is properly cited

DATES: Received 19 October 2017; received in revised form 28 November 2017; accepted 31 December 2017

Keywords: Climate change, drought frequency, standardized precipitation index, rainfall variations 
Climate change is a shift in climate usually takes place over an extended period of 150 years or more with clear and permanent impact on the ecosystem (Ayoade, 2002 cited in(Ayoade, 2016). Nasi et al. (2008) observed that climate change and biodiversity losses are two real and related challenges of our time. In Ethiopia, there has been a warming trend in the annual minimum temperature over the past 55 years (1951-2006). It has been increased by about $0.37{ }^{\mathrm{O}} \mathrm{C}$ every ten years. The trend analysis of yearly rainfall shows that rainfall remained more or less constant when averaged over the whole country(NMA, 2007).

There is a strong debate that climate change is the most significant contemporary problem to sustainable development and the risks associated with climate change will become more severe over time (IPCC, 2001, Hansen et al., 2006, FAO, 2010, WMO, 2015). While there has been a constant debate over the degree, agent of the change, and methods to address the emerging risks but there is no doubt and debate over the fact that climate has been changing from the very beginning of the Earth's history (IPCC, 2007a).

According to Food and Agricultural Organization (FAO, 2010), due to climate change and variability almost one billion people experienced hunger in 2010 globally. Perhaps, other billions are thought to suffer from hidden famine, in which essential micronutrients are missing from their daily food consumption with consequent risks of physical and mental impairment (Foresight, 2011).

In East Africa, precipitation patterns are more variable(Hulme et al., 2001). By the next three decades,(in 2050) parts of tropical Eastern Africa will likely experience 5 to $20 \%$ increased rainfall amount from December to February, and 5 to $10 \%$ declined rainfall amount from June to August. Climatic variations of this extent will have a negative implication on the water resources, agriculture, human health, coastal development, tourism, and biodiversity (WWF, 2006).

Due to various climate risks, East Africa is one of the most food-insecure regions of the continent (Slegers and Stroosnijder, 2008, Demeke et al., 2011, Gray and Mueller, 2012). The high dependence on rain-fed agriculture in these areas results in a quasi-linear relationship between grain yields, seasonal rainfall recipients, and food deficits (Funk et al., 2008). Specifically, in Ethiopia, chronic food insecurity affects $10 \%$ of the population; even in average rainfall years these households cannot meet their food needs and rely partly on food assistance (Fraser, 2007, Demeke et al., 2011).
Climate change with anticipated long-term changes in rainfall patterns and shifting temperature zones are expected to have adverse effects on agriculture (Nhemachena and Hassan, 2007) and causes a shift in animal and plant species (Önöz and Bayazit, 2003). In Ethiopia, the mean annual temperature has increased by $1.3^{\circ} \mathrm{C}$ between 1960 and 2006 (McSweeney et al., 2007). Besides, as a result of global warming, Ethiopia is predicted to experience heightened rainfall variability with both increased flooding and droughts (Deressa, 2010).

Drought is the state of adverse and widespread, hydrological, environmental, economic, and social impacts due to less than generally expected water amount (Karavitis, 1999, Karavitis et al., 2011). The primary cause of any drought is a deficiency in precipitation. Specially, the timing, distribution, and intensity of this deficiency in relation to the existing water storage, demand, and use (Karavitis et al., 2011). This deficiency may result in water shortage necessary for the functioning of natural ecosystems, and pertaining to human activities. Thus, the objective of this paper is to report on the investigation of the climatic variations and drought frequency in Dejen district, Nile Basin of Ethiopia.

\section{MATERIALS AND METHODS}

Study area: Dejen district is located in west-central Ethiopia (Fig.1) at a road distance of $335 \mathrm{~km}$ south of the regional state capital, Bahir Dar, and $230 \mathrm{~km}$ northwest of the capital city of Ethiopia, Addis Ababa in the East Gojjam zone of the Amhara Regional State on the edge of the canyon of the Blue Nile. The district lies between longitude $38^{\circ} 6^{\prime} \mathrm{E}$ and $38^{\circ} 10^{\prime} \mathrm{E}$, and between latitude $10^{\circ} 7^{\prime} \mathrm{N} 10^{\circ} 11^{\prime} \mathrm{N}$, with an elevation between 1071 and 3000 meters above sea level (m.a.s.1).

The climate of the district is traditionally classified based on altitude and temperature. The annual average temperature and total annual rainfall of the district range between $20^{\circ} \mathrm{C}$ and $24^{\circ} \mathrm{C}$ and $800 \mathrm{~mm}$ and 1200 $\mathrm{mm}$, respectively. The study district is categorized into three traditional climatic zones. $41 \%$ highlan, $31 \%$ midland, and $28 \%$ lowland (DDARDO, 2016)and (DDEPO, 2016). 


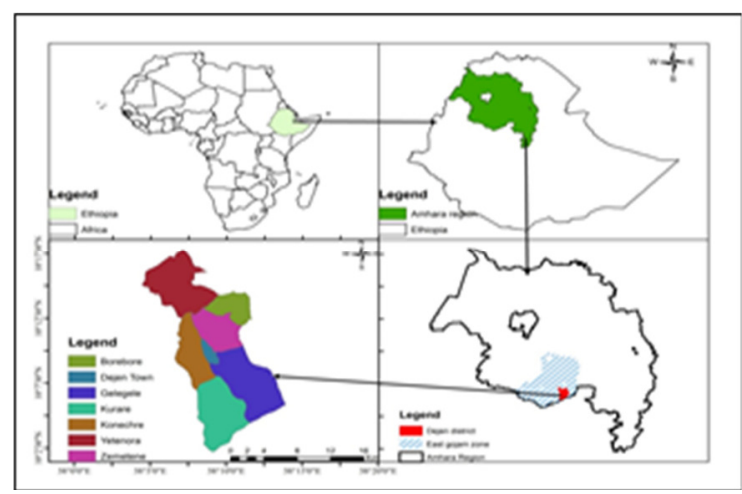

Fig 1. The study area

Rainfall is of a bimodal type- short and long rains. The short rains (Belg) fall during April-May while the long rains (Meher) occur during June - September. In the past eight years, due to climate change impacts, the district loses 50,555 quintals of crops, which has the potential to feed 27,701 individuals (DDARDO, 2016).

Data: This study used longitudinal data as repeated time series over the period 1979-2014. The local climate stations were not accurately recorded. As a result, the temperature, and rainfall data were extracted from Global Weather Data for Soil and Water Assessment Tool (SWAT) without the need of local meteorology station for the period of 36 years (19792014). The baseline period for climate data was according to the followingIPCC (1994) criteria; these were the recent average climate in the study area, sufficient duration to encompass a range of climatic variations, covering an extended period for which data on temperature and rainfall are abundant, adequately distributed over space, readily available, including data of sufficiently high quality for intended use. A popular climatological baseline period is the no overlapping 30year "normal" period as defined by the World Meteorological Organization (WMO). Due to the criterion listed above, this study used the most recent baseline period as reference period (from 1979-2014). The monthly missed values for global data were filled using pcpSTAT.

Data analysis: Pearson's Product Moment Correlation: Pearson's Product Moment Correlation is a statistical measure of the strength of and relationships between two data sets (See Table1). The Pearson's product-moment correlation ( $r$ ) was used to describe the relationships between the temperature and rainfall data over time. The computation formula for Pearson's product- correlation coefficient (r) as used by McKee et al. (1993) can be presented as:

$$
r=\frac{\sum(x-\bar{x})(y-\bar{y})}{\sqrt{\sum}(x-\bar{x})^{2} \sqrt{\sum}(y-\bar{y})^{2}}
$$

Where, $\mathrm{r}=$ Pearson correlation between $\mathrm{X}$ and $\mathrm{Y}$; $\sum X=$ sum of the data in $X$ distribution; $\sum Y=$ sum of the data in $\mathrm{Y}$ distribution; $\sum \mathrm{XY}=$ sum of the product of $\mathrm{X}$ and $\mathrm{Y} ; \sum \mathrm{X}^{2}=$ sum of the squared; $\sum \mathrm{Y}^{2}=$ sum of the squared $\mathrm{Y} ;\left(\sum \mathrm{XY}\right)^{2}=$ squared sum of $\mathrm{X} ;\left(\sum \mathrm{Y}^{2}\right)=$ square of the sum of $Y$; $n=$ number of pairs of the measurement (rainfall over time and temperature over time). $\mathrm{X}$ can be taken as time (from 1 to 36 years), $\overline{\mathrm{X}}=$ mean of time. $Y$ can be observed temperature /rainfall over the years. $\bar{Y}$, mean of temperature/rainfall. For a given observation $\mathrm{xi}$, the quantity $(\mathrm{x}-\overline{\mathrm{x}})$ will be positive if it is above the mean and negative if the observation is below the mean. It is also applied for the " $y$ " observations. The r-value can range from -1 to +1 .

Table 1 Pearson's correlation coefficient(r) value range and its relationship with temperature and rainfall data over time

\begin{tabular}{cc}
\hline r-value & Relationship \\
\hline \pm 0.0 to \pm 0.20 & Negligible \\
\pm 0.21 to \pm 0.40 & Low \\
\pm 0.41 to \pm 0.60 & Moderate \\
\pm 0.61 to \pm 0.80 & Substantial \\
\pm 0.81 to 0.99 & Very high \\
\pm 1 & perfect relationship \\
\hline Adapted from Falaki et al. $(2013)$
\end{tabular}

\section{Simple linear regression}

The regression coefficient of the interpolated regression line slope coefficient was computed from the climate data based on Mongi (2010). This type of trend line used the following linear equations to calculate the least square fit for a line using Microsoft Excel:

$Y=\beta x+c$

Where $\mathrm{Y}$ is physical factor (change in temperature and rainfall): $\mathrm{B}$ is slope of the regression equation: $\mathrm{X}$ is number of years from 1979-2014(36 years), $\mathrm{C}$ is regression constant

Standardized precipitation anomaly index (SPI): The procedure of standardization was used to transform rainfall and temperature data to come up with standardized anomalies. It used to determine periods of anomalously dry and wet events. The temperature and rainfall data were standardized using the following equation as used by McKee et al. (1993) and Svoboda et al. (2012).

$$
S P I=\frac{X-\bar{X}}{\sigma}
$$

Where; SPI refers to rainfall anomaly (irregularity and precipitation deficit) over the years; $X$ is the observed rainfall in the year (1979-2014); $\bar{X}$ refers the mean annual rainfall over the years (1979-2014); $\sigma$, refers the 
standard deviation of rainfall over the year (19792014).

McKee et al. (1993) and Svoboda et al. (2012) defined the criteria for a "drought event" for any of the time steps and classified the SPI to identify various drought intensities(Table 2).

Table2 Standardized Precipitation Index (SPI) categories to identify drought intensities

\begin{tabular}{ll}
\hline SPI values & Category \\
\hline $2.0+$ & Extremely wet \\
1.5 to 1.99 & Very wet \\
1.0 to 1.49 & Moderately wet \\
-0.99 to +0.99 & Normal \\
-1.0 to -1.49 & Moderately dry \\
-1.50 to -1.99 & Very dry \\
-2 or less & Extremely dry \\
\hline
\end{tabular}

Adapted from McKee et al. (1993) and Svoboda et al. (2012)

Runs and t-test: Trends were examined using runs test of randomness with the rainfall, and temperature data. In statistical terms, the purpose of trend analysis is to determine if a series of observations of a random variable is increasing or decreasing with time, or whether the probability distribution has changed with time. An independent sample t-test was used to examine whether there are statistical differences in the mean temperature and rainfall measures for the period 1979-2014. The 36 years of daily weather data were transformed to monthly and analyzed for changes in pattern and variability.

Test statistics: A runs is a sequence of + signs which is followed and proceeded by - sign. To use runs test, we first compute the median of the data over the period 1979-2014. Then, go through the data series making values above the median with $(+)$ signs which those below the median with (-) sign.

$$
\mathrm{Z}=\frac{r-\frac{n}{2}-1}{\sqrt{n^{2}-2 n / 4(n-1)}}
$$

Where; $r=$ Number of runs, $n=$ sample size (36 years of temperature and rainfall data); If the $\mathrm{Z}$ lies outside the range of -1.96 and +1.96 using a $5 \%(a=0.05)$ level of significance, the hypothesis that the series contains the number of runs expected in a random sequence is rejected. The Run's test only tells us the randomness. Whether the calculated correlation coefficient is significant was tested by t-test statistics.

$$
t=\frac{r \sqrt{n-2}}{\sqrt{1-r^{2}}}
$$

Where $\mathrm{r}$ is the calculated correlation coefficient, and $\mathrm{n}$ is the sample size. The degree of freedom for the t-test is $(\mathrm{n}-2)$.

\section{RESULTS AND DISCUSSION}

Agriculture, water resources, health, and energy are inherently sensitive to changes in climatic conditions. Therefore, it is pertinent to examine the characteristics of climatic elements, mainly temperature, and rainfall variations over the period 1979-2014.

Trends in temperature: The primary goal of a time series analysis was to understand seasonal change over time to take appropriate adaptation measures. The results of the meteorological data indicate that the mean annual temperature in the study area had been increasing trends for the last three decades. The temperature data were analyzed using correlation coefficient and simple regression using equation (1 and 2 ). Based on the description of runs test in equation (4), the maximum and minimum temperatures were tested for randomness. The median for maximum temperature is 27.10; the number of runs(r) is 8 . The sample size $(n)=36$. The values above the median were marked $(+)$ while those below the median were marked (-). The median for minimum temperature is 10.34 , the number of runs $(r)$ is 12 and sample size $(n 1=n 2)=36$.

The $\mathrm{Z}$-test for the maximum temperature was -3.72 . The study district maximum temperature series gives a $\mathrm{Z}$ value of -3.72 which is outside the range. Therefore it is concluded that the maximum temperature series in Dejen district over the period 1979-2014 was not random. This implies there is a trend over the time 1979-2014 in maximum temperature. In the study area, the minimum temperature series gives a $\mathrm{Z}$ value of 2.3583 which is outside the range $( \pm 1.96)$, and it implies that the minimum temperature series in Dejen district over the period 1979-2014 was not random.

Thus, the result indicates there is a trend over the time 1979-2014 in both maximum and minimum temperature. The correlation coefficient (r) shows the positive relationship in both maximum temperature (0.64) and minimum temperature (0.74) (Table 3). There is a significant increase in both maximum $(6.29>1.70)$ and minimum temperature $(6.42>1.70)$ at 0.05 significant level. Therefore, there is a significant increase in temperature over the past 36 years

Table 3 Testing statistics using t-test (Equation1 and 5)

\begin{tabular}{ccccc}
\hline Temperature & Correlation coefficient $(\mathrm{r})$ & Calculated d value (t) & Degree of fredom (DF) & Table value \\
\hline Av. Max. Temp $(1979-2014)$ & 0.64 & 6.28816 & 3.4 & 1.7 \\
Av. Min. Temp. $(1979-2014)$ & 0.74 & 2.429 & 3.4 & 1.7 \\
\hline \multicolumn{4}{c}{ Computed from Global Weather Data for soil and water assessment [http://globalweather.tamu.edu/]1979-2014) }
\end{tabular}


The estimated trend line for mean temperature is $\mathrm{y}=$ $0.046 x+9.453$ (Fig.2). This trend line has a positive slope which shows as time increases; there is an increase in temperature. The mean temperature has increased by $1.66^{\circ} \mathrm{C}$ in the study district from 1979 to2014. Both the maximum, minimum and mean temperature was analyzed using equation (1 and 2). The result indicates that these trends show significant increasing patterns over the observation period. The maximum temperature increased faster compared to minimum temperature in the study area. This means the maximum temperature rose by $2.16{ }^{\circ} \mathrm{C}$ and the minimum temperature increased by $1.91{ }^{\circ} \mathrm{C}$ over the period 1979-2014 (Fig. 2).

The Pearson's product-moment result of maximum temperature $(\mathrm{r}=0.64)$ shows, there is a reasonable relationship in a positive direction. This means, as time increase, there is a moderate increase in the maximum temperature. The minimum temperature also has a moderate relationship in the positive direction $(r=0.74)$. The direction of the temperature in the study area was found in line with a study in Tabora by Mongi (2010) and study in Ethiopia by Menberu (2016) which found out that both minimum and maximum temperature show increasing trends. Also, the results differ from that of Shinyanga rural district study by Lyimo and Kangalawe (2010) who reported both minimum and maximum temperature showed an increasing trend but the minimum temperature increased sharply while the maximum temperature increased gradually. This implies that different areas experiencing similar climatic conditions can experience changes in climate differently.

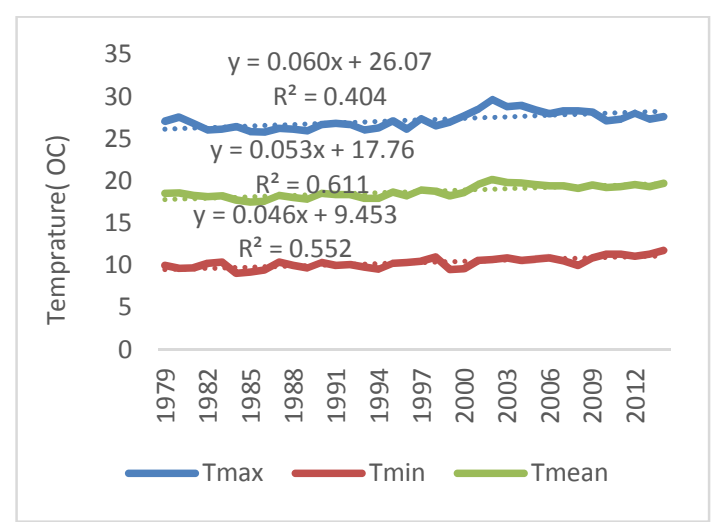

Fig. 2 Variations in temperature (1979-2014). Computed from Global Weather Data for soil and water assessment [http://globalweather.tamu.edu/]1979-2014). *Tmax, Tmin, and Tmean represent maximum, minimum and mean temperature respectively.
Increase in temperature adversely affects crops mainly in tropical and subtropical where heat has become a limiting factor for crop production. The rise in temperature also increase evapotranspiration rate of plants and increase chances for severe drought (Intergovernmental Panel on Climate change (IPCC, 2007). Based on study by Deressa and Hassan (2009), climate change will reduce Ethiopian crop yields. Based on their studies by using three different models under different scenarios, income per hectare will decrease by $9.71 \%-303.27 \%$ by 2050 and $10.34-418.01 \%$ by 20100. Besides, the increasing temperature trends in the study area has a paramount impact on water, land and vegetation resources through exacerbating evapotranspiration with negative consequences on the productive capacity of these valuable resources.

Trends in rainfall: The Pearson's product-moment result shows, there is a reasonable relationship in a negative direction (-0.531) (Table 4). This implies, as time increase, there is a reasonable decrease in the rainfall. Based on the runs test of randomness equation (4), the annual rainfall was not random with the $\mathrm{Z}$ value of -2.029 , which means there is a trend over the period 1979-2014 in Dejen district, Nile Basins of Ethiopia. The median for annual rainfall is 981.10 ; the numbers of runs (r) are 13.

The sample size $(n)=36$. Then, values above the median are marked $(+)$ while those below the median are marked (-). The $\mathrm{Z}$-test for the annual rainfall is 2.0292 . The study district yearly rainfall series gives a $\mathrm{Z}$ value of -2.0292 which is outside the range $( \pm 1.96)$. Therefore it is concluded that the annual rainfall series in Dejen district over the period 1979-2014 is not random. This indicates there is a trend over the period 1979-2014 in annual rainfall. The correlation coefficient (r) shows a negative relationship in yearly rainfall (-0.531) over the period 1979-2014 (Table 4).

This indicates rainfall is a decreasing trend. T-test statistics was used to test the significant level of the correlation coefficient value (Table 4) based on Equation (5). The decreasing trend of rainfall has a significant amount of annual rainfall (3.66>1.70). Therefore, there is a significant decline in rainfall amount over the past three decades.

The total annual rainfall distribution is declining from time to time (Fig. 3) at a significant rate. Besides a significant decrease in rainfall, there is also a problem in timing (late onset and early cessation). The longterm reduced amount of rainfall computed using simple linear regression for the observed period indicated that 
the rainfall declined by 399.96 millimeters over the period 1979-2014.

Table 4. Testing statistics for annual rainfall (Equation 1and5)

\begin{tabular}{ccccc}
\hline & $\begin{array}{c}\text { Correlation } \\
\text { coefficient }(\mathrm{r})\end{array}$ & $\begin{array}{c}\text { Calculated } \\
\text { value }(\mathrm{t})\end{array}$ & $\begin{array}{c}\text { Degree of } \\
\text { freedom }(\mathrm{DF})\end{array}$ & $\begin{array}{c}\text { Table } \\
\text { Value }\end{array}$ \\
\hline Annual & -0.531 & 3.66 & 34 & 1.70
\end{tabular}

rainfall

Computed from Global Weather Data for soil and water assessment [http://globalweather.tamu.edu/]1979-2014).

In Ethiopia rainfall is the most important climatic factor influencing the growth characteristics and productivity of agricultural crops. Therefore, these anomalies have the potential to cause undesirable effects on crop production and food security of rural communities whose mainstay is agriculture.

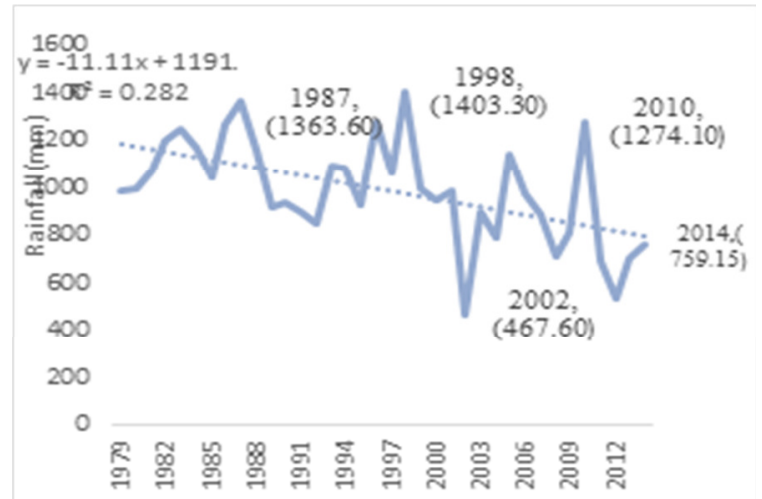

Fig. 3 Variations in annual rainfall. Computed from Global Weather Data for soil and water assessment [http://globalweather.tamu.edu/]1979-2014)

In the study area, the decreasing trend in rainfall is in contrary to the projections of climate models for East Africa. The IPCC (2007) projected that except in very few places, rainfall is likely to increase in East Africa. Study by Bryan et al. (2013) in Kenya also indicated an increase in rainfall. The current international scientific consensus is that recent global warming conditions show a relatively stable long-term trend with natural variability of climate (Hansen et al., 2006). Evaporative demand or 'potential evaporation is projected to increase almost everywhere. This is because the water holding capacity of the atmosphere increases with higher temperature (Trenberth et al., 2003, Bates, 2009).

Standardized Precipitation Anomaly Index (SPI): Analysis of drought frequency, duration, and severity can help in designing appropriate actions. As a measure of drought, the standardized precipitation anomaly index was calculated on annual timescales for the study area (Table 5 and Fig. 4). The use of standardized precipitation index (SPI), may lead to a more appropriate understanding of drought duration, and spatial extent. The importance of the index could be in its simplicity and its ability to identify the beginning and end of incidents of drought. Standardized precipitation index (SPI) depicted in equation (3) shows the long-term drought pattern for the study area. The rainfall shows alternation of dry and wet years in a periodic pattern (Fig.4). From 36 years of observation, 2002 and 2012 received below the long-term average rainfall and characterized by extremely dry years while 2008, 2011, 2013, 2014 years characterized by moderately dry. The year 1983, 1986,1987,1996,1998, and 2010 were moderately wet. Among these negative patterns, the year 2002 and 2012 of extreme drought years (Table5) is in line with the National level drought history of Ethiopia. When drought begins, the agricultural sector is usually the first to be affected because of its heavy dependence on stored water.

Fig. 4 Standardised precipitation anomaly index (SPI) (1979-2014):

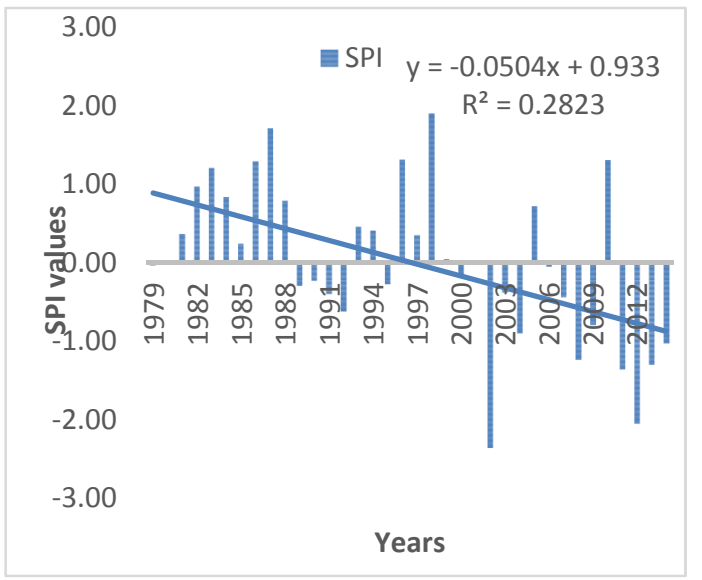

Computed from Global Weather Data for soil and water assessment [http://globalweather.tamu.edu/]1979-2014)

In Ethiopia rural communities are relying on the stored soil water, as a result; the agriculture sector would be the first system which to be affected is the mainstay of the rural community. Ethiopia is highly affected by drought with an estimated 10.2million people needing food because of crop failure. In Ethiopia, 400,000 children faced much more severe food insecurity in 2016. The normal rain season has affected the agriculture and water sources in 2016, which has resulted in the worst drought Ethiopia has seen in decades (FAO, 2016). High temperatures usually occur in conjunction with other environmental stresses. These are drought and high light intensity (Rahman, 2006) which might lead to increased crop water requirements and therefore causes scalding in cereals (Burke, 1990), disturb flowering and strongly reduce crop yield (Mackill et al., 1982, Zheng and Mackill, 1982). This means farming activities in Dejen district and places having similar settings were affected by increased temperature and drought which affects food security and well-being of the rural communities in general. The high and positive SPI values indicate surplus rainfall and may be associated with flood years 
though there is no standard to classify year in relation to flood occurrence. We can state the year 1983, 1986,1987, 1996,1998, and 2010 were the first in by the probability flood occurrence with SPI value of 1.2,1.29,1.71,1.31,1.89, and 1.31 respectively (Table 5). Lack of drinking water, the impacts of diseases outbreaks that luxuriate under high temperatures may in all probability be increased under a changing climate driven by increased temperature. For example, it is anticipated that there will be a marked increase in the scourge of malaria in Sub-Saharan Africa, where Ethiopia is located (Bruce, 1999).

Table 5 Standardized Precipitation Index(SPI) values of above and below normal wet and dry years

\begin{tabular}{cccc}
\hline Years & Annual rainfall(mm) & SPI values & Values Category \\
\hline 1983 & 1251.4 & 1.2 & Moderately wet \\
1986 & 1269.6 & 1.29 & Moderately wet \\
1987 & 1363.6 & 1.71 & Moderately wet \\
1996 & 1274.94 & 1.31 & Moderately wet \\
1998 & 1403.3 & 1.89 & Moderately wet \\
2002 & 467.6 & -2.35 & Extremely dry \\
2008 & 713.6 & -1.24 & Moderately dry \\
2010 & 1274.1 & 1.31 & Moderately wet \\
2011 & 686.6 & -1.36 & Moderately dry \\
2012 & 536.04 & -2.04 & Extremely dry \\
2013 & 699.6 & -1.3 & Moderately dry \\
2014 & 759.15 & -1.03 & Moderately dry \\
\hline Computed from Global Weather Data for soil and water assessment \\
[http://globalweather.tamu.edu/]1979-2014)
\end{tabular}

Conclusion: This study finds the need for rural communities to adopt water harvesting technologies to deal with the incidence of dry spells during the production season. Dry spell periods require farmers in Dejen district and places having similar settings to implement adaptation measures such as changing planting date, cropping system (mix cropping), and crop varieties (drought resistant species). Thus, academic institutions like Universities and research institutions should develop drought and pest-resistant and early maturing crop varieties to reduce the increasing trends of climate change and its impact on the rural communities' livelihood.

Acknowledgments: This study was sponsored by the Pan African University (PAU) a continental initiative of the African Union Commission (AU), Addis Ababa, Ethiopia. Authors would like to thank the University of Ibadan for hosting the programme.

\section{REFERENCES}

Ayoade, J. (2016). Climate change: a synopsis of its nature, causes, effects and management. Second edition, Agbo Areo Publishers, Ibadan, Nigeria.

Bates, B. (2009). Climate Change and Water: IPCC technical paper VI, World Health Organization.
Bruce (1999). The potential of world cropland soils to sequester $\mathrm{C}$ and mitigate the greenhouse effect. Environmental Science and Policy. 2:177-185.

Bryan, E; Ringler, C; Okoba, B; Roncoli, C; Silvestri, S; Herrero, M (2013). Adapting agriculture to climate change in Kenya: Household strategies and determinants. Journal of environmental management, 114, 26-35.

Burke, J. (1990). High temperature stress and adaptations in crops. Plant biology (USA).

DDARDO (2016). Dejen District Agricultural and Rural Development Office(DDRDO), Annual Report ,East Gojjam zone, Dejen, Ethiopia.

DDEPO (2016). Dejen District Environmental Protection Office(DDEPO),East Gojjam zone, Dejen, Ethiopia.

Demeke, AB; Keil, A; Zeller, M (2011). Using panel data to estimate the effect of rainfall shocks on smallholders food security and vulnerability in rural Ethiopia. Climatic change, 108, 185-206.

Deressa, T. T. (2010). Assessment of the vulnerability of Ethiopian agriculture to climate change and farmers' adaptation strategies.

Deressa, T. T. \& Hassan, R. M. (2009). Economic impact of climate change on crop production in Ethiopia: evidence from cross-section measures. Journal of African economies, 18, 529-554.

Falaki, A; Akangbe, J; Ayinde, O (2013). Analysis of climate change and rural farmers' perception in North Central Nigeria. Journal of Human Ecology, 43, 133-140.

FAO (2010). Climate change and food safety: A review. Food Research International, 43, 17451765.

FAO (2016). ,Food and Agriculture Organization of the United Nations and the UN-World Food Programme (WFP) and the European Union. A pilot report assessing global food security, Rome, Italy.

Foresight, U. (2011). The Future of Food and Farming. Final Project Report. The Government Office for Science, London.

Fraser, E. D. (2007). Travelling in antique lands: using past famines to develop an adaptability/resilience framework to identify food systems vulnerable to climate change. Climatic Change, 83, 495-514.

Funk, C; Dettinger, MD; Michaelsen, JC; Verdin, J; Brown, ME; Barlow, M; Hoell, A (2008). Warming of the Indian Ocean threatens eastern and southern African food security but could be mitigated by agricultural development. Proceedings of the national academy of sciences, 105, 11081-11086. 
Gray, C; Mueller, V (2012). Drought and population mobility in rural Ethiopia. World development, 40, 134-145.

Hansen, J; Sato, M; Ruedy, R; Lo, K; Lea, DW; Medina-Elizade, M (2006). Global temperature change. Proceedings of the National Academy of Sciences, 103, 14288-14293.

Hulme, M; Doherty, R; Ngara, T; New, M; Lister, D (2001). African climate change: 1900-2100. Climate research, 17, 145-168.

IPCC (1994). IPCC Climate Change Radiative Forcing of Climate Change and an Evaluation of the IPCC IS92 Emission Scenarios. Cambridge, UK: Cambridge University Press.

IPCC (2001). Climate change: Impacts, Adaptation, and Vulnerability. Contribution of Working Group II to the Third Assessement Report, Cambridge University Press,Cambridge,UK.

IPCC (2007). Climate Change: Climate Change Impacts, Adaptation and Vulnerability.The Fourth Assessment Report of the Intergovernmental Panel on Climate Change. Geneva, Switzerland.

IPCC (2007a). Climate chnage: The Phyiscal Sciencebasis.Contribution of working group I to the fourth Assessment Report of the Intergovernmental Panel on Climate change, . UK.: Cambridge University Press, Cambridge,

Karavitis, CA (1999). Decision support systems for drought management strategies in metropolitan Athens. Water International, 24, 10-21.

Karavitis, CA; Alexandris, S; Tsesmelis, DE; Athanasopoulos, G (2011). Application of the standardized precipitation index (SPI) in Greece. Water, 3, 787-805.

Lyimo, JG; Kangalawe, RY (2010). Vulnerability and adaptive strategies to the impact of climate change and variability. The case of rural households in Semiarid Tanzania. Environmental Economics, 1, 88-96.

Mackill, D; Coffman, W; Rutger, J (1982). Pollen shedding and combining ability for high temperature tolerance in rice. Crop Science, 22, $730-733$.

McKee, TB; Doesken, NJ; Kleist, J (1993). The relationship of drought frequency and duration to time scales. Proceedings of the 8th Conference on Applied Climatology. American Meteorological Society Boston, MA, 179-183.

McSweeney, C; New, M; Lixcano, G (2007). EthiopiaUNDP climate change country profiles. UNDPEthiopia.

Menberu, T. (2016). Rural households' agricultural land vulnerability to climate change in Dembia woreda, Northwest Ethiopia. Environmental Systems Research, 5, 14.

Mongi, H; Majule, AE; Lyimo, J (2010). Vulnerability and Adaptation of Rain-fed Agriculture to climate change and Variability in Semi-arid Tanzania African Journal of Environmental Science and Technology, 371-381.

Nasi, R; Brown, D; Wilkie, D; Bennett, E; Tutin, C; Van Tol, G; Christophersen, T (2008). Conservation and use of wildlife-based resources: the bushmeat crisis. Secretariat of the Convention on Biological Diversity, Montreal. and Center for International Forestry Research (CIFOR), Bogor. Technical Series, 50.

Nhemachena, C; Hassan, R. (2007). Micro-level analysis of farmers adaption to climate change in Southern Africa, Intl Food Policy Res Inst.

NMA (2007). Climate change national adaptation programme of action (Napa) of Ethiopia. National Meteorological Services Agency(NMA), Ministry of Water Resources, Federal Democratic Republic of Ethiopia, Addis Ababa.

Önöz, B; Bayazit, M (2003). The power of statistical tests for trend detection. Turkish Journal of Engineering and Environmental Sciences, 27, 247251.

Rahman, H (2006). Number and weight of cotton lint fibres: variation due to high temperatures in the field. Australian journal of agricultural research, 57, 583-590.

Slegers, M. F; Stroosnijder, L. (2008). Beyond the desertification narrative: a framework for agricultural drought in semi-arid East Africa. AMBIO: A Journal of the Human Environment, 37, 372-380.

Svoboda, M., Hayes, M; Wood, D. (2012). Standardized precipitation index user guide. World Meteorological Organization Geneva, Switzerland.

Trenberth, K; Dai, A; Rasmussen, R; Parsons, D (2003). The changing character of precipitation, B. Am. Meteorol. Soc., 84, 1205-1217, doi: 10.1175. BAMS-84-9-1205.

WMO (2015). Statement on the status of the global environment, Geneva, Switzerland, Japan Meteorological Agency, in cooperation with the World Meteorological Organization.

WWF (2006). World Wide Fund(WWF):Climate change impacts on East Africa,A Review of the Scientific Literature, Gland, Switzerland.

Zheng, K; Mackill, D (1982). Effect of high temperature on anther dehiscence and pollination in rice. Sabrao J, 14, 61-66. 